\title{
SOMATIC HYBRID PLANTS OF POTATO AND TOMATO REGENERATED FROM FUSED PROTOPLASTS
}

\author{
by \\ GEORG MELCHERS \\ Max-Planck-Institut für Biologie, \\ Corrensstrasse 45, D-7400 Tübingen \\ MARIA D. SACRISTÁN \\ Institut für Angewandte Genetik der Freien Universitāt \\ Albrecht-Thaer-Weg 6, D-1000 Berlin 33 \\ and \\ ANTHONY A. HOLDER \\ Department of Physiology, Carisberg Laboratory, \\ Gamle Carlsberg Vej 10, DK-2500 Copenhagen, Valby
}

Keywords: Ribulose bisphosphate carboxylase, fraction 1 protein, isoelectric focusing, chromosome numbers

Mesophyll protoplasts of Lycopersicon esculentum Mill. var. cerasiforme (Dunal) Alef, mutant yellow green 6, Rick and protoplasts of a liquid callus culture of the dihaploid strain HH258 of Solanum tuberosum L. were prepared and many fusion products were visible after the protoplasts were incubated together first in the presence of polyethylene glycol and then with a high $\mathrm{Ca}^{2+}$ ion concentration. The protoplasts were transferred to a rich medium and the resultant calli were cultured. Some calli regenerated normal green shoots which were transferred to soil or grafted onto a tomato stock. The subunit polypeptide pattern of ribulose 1,5-bisphosphate carboxylase prepared from leaf material of four regenerated plants was analyzed by isoelectric focusing. The ribulose bisphosphate carboxylase enzyme oligomer in the four plants contained the small subunit products resulting from the expression of both tomato and potato nuclear genes proving these plants to be somatic hybrids between tomato and potato. In three of the four plants the large subunit polypeptides and hence the functional chloroplast DNA were from tomato whereas in the fourth the large subunit and therefore the chloroplast DNA was derived from potato. The plant material was insufficient to establish the chromosome numbers precisely, however counts close to 50 which is near to the expected 48 were obtained for three of the hybrids whereas in the fourth a number close to 72 was observed. In the absence of a selection system against the potato parent, the analysis of ribulose bisphosphate carboxylase provides a convenient marker to demonstrate the hybrid nature of the plants. 


\section{INTRODUCTION}

The development of methods to fuse plant protoplasts reproducibly $(19,22,43)$ has made it possible to produce cell hybrids and to regenerate from these in certain instances plants which are somatic hybrids. Most of the somatic hybrids produced so far can also be obtained by sexual hybridization $(7,27,29,30,32,36,37,38)$. Recently somatic hybrids have been produced by fusion of protoplasts from species which cannot be sexually hybridized either in one direction (25), at a certain ploidy level or without the aid of embryo culture (37). In cases of pure gamete incompatibility somatic hybridization is likely to be successful, but in such cases sexual hybridization by in vitro fertilization can also be a way to achieve the hybrid. In cases of zygote incompatibility either alone or in combination with gamete incompatibility, the fusion of protoplasts is unlikely to lead to hybrid plants. As discussed by ZENKTELER and MeLCHERS (45) in situ observation of embryo development after sexual crosses cannot give decisive information on the type of incompatibility involved since impaired zygote development can be caused by inhibition from maternal tissues. Such inhibition is absent in callus and embryo cultures.

To the best of our knowledge sexual hybrids between potato (Solanum tuberosum, L.) and tomato (Lycopersicon esculentum Mill.) have not been described. The possibility to fuse the protoplasts between these two species is not surprising as incompatibility of cell fusion generally is absent even between animal and plant cells (6). Division and cell cultures from fusion products have been obtained in as diverse combinations as fusions of mouse and human cells or soybean (Glycine max L. Merr.) and Nicotiana glauca Grah. cells (18, 44). Regeneration of plants from hybrid callus cultures is unpredictable. In many plant species regeneration of plants from non-hybrid somatic callus tissue is not possible at present. One might expect that the chances of regenerating plants from somatic fusion products diminishes with increasing taxonomic distance between the partners involved, but the presently known somatic hybrids are too few to permit an evaluation of this hypothesis. Cases are known in which zygote incompatibility is caused by a single allele difference $(15,16,26)$. It is of interest to note that a sexual hybrid between Petunia parodii W.C.S. and Nicotiana tabacum L. has been described (31). Although somatic hybridization between Petunia parodii and $\mathrm{P}$. hybrida readily yielded plants (32) it has so far been impossible to regenerate plants from fusions of N. tabacum and P. hybrida (45).

It has been reported by MELCHERS (28) that protoplasts from cell lines of dihaploid Solanum tuberosum with 24 chromosomes and the diploid Lycopersicon esculentum with 24 chromosomes can be readily fused. This can be directly seen from the protoplasts of Figure 1 which have resulted from a fusion of a colourless potato protoplast and a green tomato protoplast. Since the dihaploid potato cell line has been kept as a submersed callus culture the protoplasts used in the experiments contain only colourless proplastids. The tomato protoplasts originated from mesophyll cells of green-house grown plants and therefore contain light green chloroplasts. The cytoplasms of the fused protoplasts in Figure 1 have not yet mixed and tomato-potato fusions can therefore be recognised as protoplasts with a colourless and a green part.

The present communication presents chromosomal counts and an analysis of ribulose-1,5bisphosphate carboxylase (RuBPCase, E.C. 4.1.1.39) of putative somatic hybrid plants regenerated from callus tissue obtained in the above mentioned fusion experiments.

Ribulose-1,5-bisphosphate carboxylase from higher plants can be dissociated into two types of subunit. Isoelectric focusing $(23,35)$ and peptide mapping $(2,21)$ studies of the subunits from some Nicotiana species have shown that the large subunit (MW 55,000) is maternally inherited and that the small subunit (MW 12,000-

Abbreviations: RuBPCase $=$ ribulose-1,5-bisphosphate carboxylase: $\mathrm{PVP}=$ polyvinylpyrrolidone: SDS $=$ sodium dodecyl sulphate. 
15,000 ) is inherited in a Mendelian fashion. The large subunit gene has been located on chloroplast DNA $(4,10)$. The small subunit is synthesized on cytoplasmic polysomes (33) and

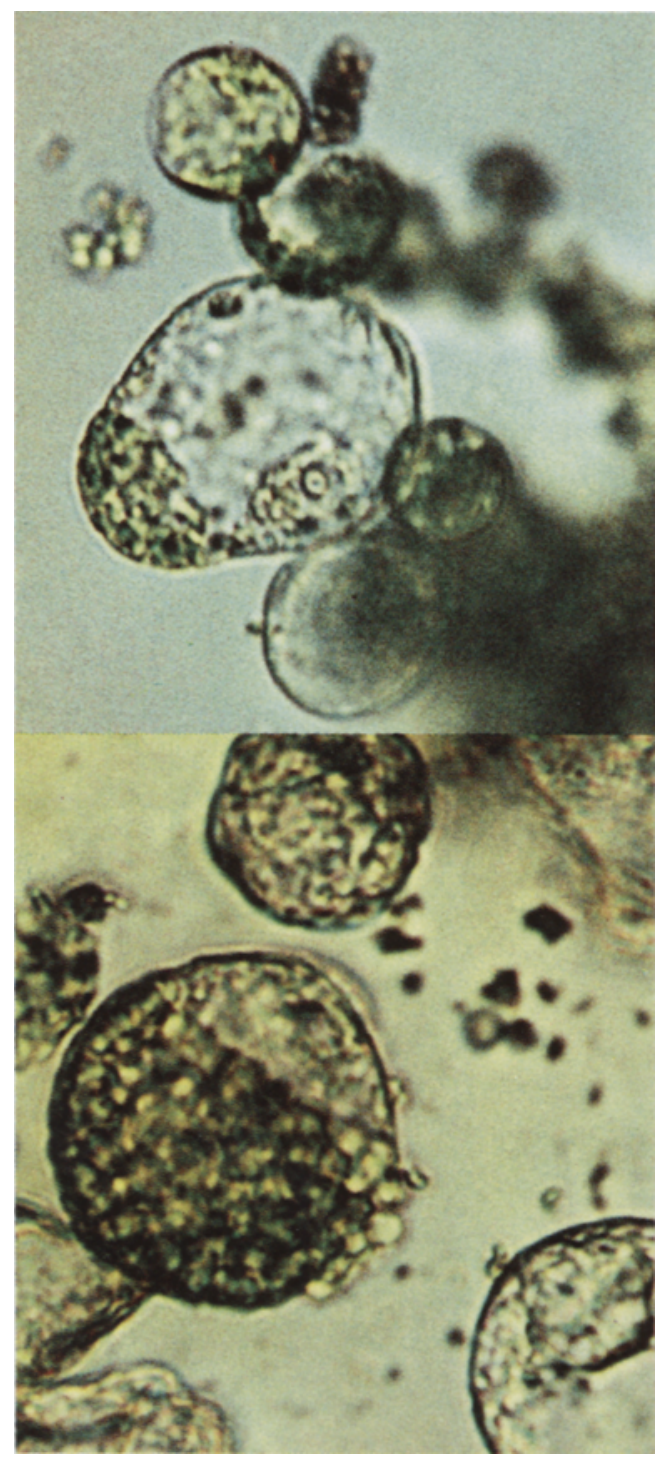

Figure 1. Protoplasts arisen by fusion of tomato and potato protoplasts. The cytoplasmic part of the tomato (Lycopersicon esculentum var. cerasiforme mut. yellow green 6) is recognizable by the green chloroplasts present in the tomato mesophyll protoplasts. The cytoplasmic part of the potato (Solanum tuberosum, dihaploid stock HH 258) is colourless as the potato protoplasts were made from submersed cultured callus cells with proplastids. transported into the chloroplast $(5,13)$. Isoelectric focusing of the S-carboxymethylated RuBPCase has been used to provide phenotypic markers of chloroplast and nuclear genomes to study nuclear-cytoplasmic relationships in the evolution of plant species $(3,8,9,11,39)$ and in the analysis of sexual interspecific hybrids (35). KUNG et al. (24) have also used this approach to investigate the result of interspecific protoplast fusion within the genus Nicotiana. The present results demonstrate differences in both the large and small subunits of RuBPCase from potato and tomato which have been used to demonstrate the hybrid nature of four plants produced by fusion of tomato and potato protoplasts.

\section{MATERIALS AND METHODS}

\subsection{Preparation of protoplasts}

Protoplasts of Solanum tuberosum were prepared from the dihaploid stock $\mathrm{HH} 258$ from the Max-Planck-Institut für Züchtungsforschung, Köln-Vogelsang. Plants can be regenerated from callus cultures of this line (1). This potato stock as grown in Tübingen was largely self-fertile, but non-homogeneous with regard to leaf form and flower colour. Submersed callus of this stock is kept in continuous culture at Tübingen (28).

From a culture started on Sept. 19, 1976 in LS1 medium (1) $50 \mathrm{ml}$ cell suspension was combined with $50 \mathrm{ml} \mathrm{E}_{4}$ solution (19) containing 0.7 M-glucose, $6 \mathrm{~mm}-\mathrm{CaCl}_{2}, 0.7 \mathrm{~mm}-\mathrm{NaH}_{2} \mathrm{PO}_{4}, 3$ $\mathrm{mM}-2[\mathrm{~N}$-morpholino]ethane sulfonate and adjusted to $\mathrm{pH} 5.7$ with $\mathrm{NaOH}$. The $\mathrm{E}_{4}$ solution also contained $2 \%$ cellulase Onozukar R-10 (Kinki Yakult Manufact. Co. Ltd. 8-12 Nishinomiya, Japan), 2\% Rohament P (Röhm and Haas, Darmstadt, FRG) and $0.5 \%$ pectinase No. P-4625 (Sigma, St. Louis, USA). The incubation mixture had a $\mathrm{pH}$ of 5.8 and the treatment lasted 4-5 hours.

Mesophyll protoplasts of tomato were prepared from light green leaves of the mutant yellow green 6, in Lycopersicon esculentum var. cerasiforme. Seed of the mutant was kindly supplied by Dr. C. M. RICK, University of California, Davis. The mutant has light green leaves if grown in a shaded green-house but 


\section{Table I}

Protocols of the callus tranfers and shoot regenerations of the 4 relevant groups of plants regenerated from protoplast fusions of potato and tomato.

\begin{tabular}{|c|c|}
\hline Group & $1 \mathrm{~b} / 2 \mathrm{~h} / 3$ (Figures $2 \mathrm{a}$ and $\mathrm{b}$ ) \\
\hline Date: & \\
\hline 1.03 .77 & fusion and protoplasts plated on $8 \mathrm{p}$ medium \\
\hline 24.03. & dilution on liquid $8 p$ medium \\
\hline 4.04. & dilution on agar with $8 \mathrm{p}$ medium \\
\hline 28.04. & transfer of small light calli to D2s medium (34) \\
\hline 12.05 . & transfer of grown calli to MS13K medium (1) + coconut extract \\
\hline 26.05 . & transfer of healthy tissue to MS13K medium \\
\hline 15.06. & transfer to fresh MS13K medium \\
\hline 18.07. & transfer to fresh MS13K medium \\
\hline 11.08 . & transfer of healthy portions to fresh MS13K medium \\
\hline 16.09 . & transfer of callus to fresh MS13K medium \\
\hline 16.09. & isolation of regenerated shoots $(\mathrm{S} 1, \mathrm{~S} 2)$ to $\mathrm{NO} 1$ medium $(40)$ with $4 \mathrm{~g} \cdot \mathrm{ml}^{-1}$ sucros \\
\hline 27.09 . & isolation of regenerated shoots (S3-S5) to NO 1 medium \\
\hline 12.10. & transfer of callus to fresh MSI3K medium \\
\hline 12.10. & transfer of shoots $\mathrm{S} 1$ to $\mathrm{S} 5$ on $\mathrm{KW}$ medium (29) \\
\hline 26.10. & transfer of shoots to soil \\
\hline 24.04 .78 & grafting of shoots on tomato stock var. Supravite \\
\hline
\end{tabular}

Code:
1
$\mathrm{lb}$
$\mathrm{lb} / \mathrm{l}-4$
$\mathrm{lb} / 2 \mathrm{~h}-\mathrm{p}$
$\mathrm{lb} / 2 \mathrm{~h}$
$\mathrm{lb} / 2 \mathrm{~h}$
$\mathrm{lb} / 2 \mathrm{~h}$
$\mathrm{lb} / 2 \mathrm{~h}$
$\mathrm{lb} / 2 \mathrm{~h} / 1-3$
$\mathrm{lb} / 2 \mathrm{~h} / 3$
$\mathrm{lb} / 2 \mathrm{~h} / 3 / \mathrm{S} 1,2$
$\mathrm{lb} / 2 \mathrm{~h} / 3 / \mathrm{S} 3-5$
$\mathrm{lb} / 2 \mathrm{~h} / 3$
$\mathrm{lb} / 2 \mathrm{~h} / 3 / \mathrm{S} 1-5$

Group 6a/4z/6g (Figure 3)

Date:

1.03.77 fusion and protoplasts plated on $8 \mathrm{p}$ medium

24.03. dilution on liquid $8 \mathrm{p}$ medium

6.04. dilution on agar with $8 \mathrm{p}$ medium

6.05. dilution in agar with $8 \mathrm{p}$ medium as toplayer on bottom layer with MSI3K medium

13.07. transfer of healthy green calli on MS13 medium

16.09. transfer of healthy tissue on MS13 medium

2.11. transfer to fresh MS13 medium

2.11. isolation of regenerated shoots $(\mathrm{S} 1, \mathrm{~S} 2)$ to NO 1 medium

18.11. transfer of shoots to soil

24.04.78 grafting of shoots on tomato stock var. Supravite

Group $6 b / 1 \times / 2 a$ and $2 b \quad$ (Figures 4 and 5 )

Date:

1.03.77 fusion and protoplasts plated on $8 \mathrm{p}$ medium

24.03. dilution on liquid $8 \mathrm{p}$ medium

6.04. dilution on agar with $8 \mathrm{p}$ medium

6.05. dilution in agar with $8 \mathrm{p}$ medium as toplayer on bottom layer with MSI3K medium

13.07. transfer of healthy green calli on MS13 medium

6.09. transfer of healthy tissue on MS13

2.11. transfer to fresh MS13 medium

2.11. isolation of regenerated shoots (S1-S4) to NO 1 medium

18.11. transfer of callus to fresh MS13 medium

22.11. isolation of regenerated shoots (S5-S13) to NO 1 medium, the shoots had on the callus strong roots

Code:

6

$6 \mathrm{a}$

$6 a / 1-4$

$6 a / 4 z / 1-8$

$6 a / 4 z / 6 a-h$

$6 a / 4 z / 6 e-h$

$6 \mathrm{a} / 4 \mathrm{z} / 6 \mathrm{~g}$

$6 \mathrm{a} / 4 \mathrm{z} / 6 \mathrm{~g} / \mathrm{SI}, 2$

28.11. isolation of regenerated shoots (S14-S16) to NO 1 medium medium + $50 \mathrm{mg} / \mathrm{l}$ aureomycin

28.11. isolation of regenerated shoots (SI4-S16) to NO 1 medium

1-12. transfer of shoots S7, S8, S12, S13 to NO 1 medium, as no growth occured in the presence of aureomycin

6.12. transfer of callus to fresh MS13 medium

6.12. transfer of shoots S14-S16 to soil

6.12. transfer of shoots $(\mathrm{S} 17, \mathrm{~S} 18)$ to $\mathrm{NO} 1$ medium

6.12. transfer of shoots (S19, S20) to NO 1 medium $+25 \mathrm{mg} \cdot \mathrm{1}^{-1}$ aureomycin

Code:

6

$6 \mathrm{~b}$

$6 b / 1-5$

$6 b / 1 x / 1-8$

$6 b / 1 \times / 2 a-d$

$6 \mathrm{~b} / 1 \times / 2 \mathrm{a}$

$6 \mathrm{~b} / 1 \mathrm{x} / 2 \mathrm{a}$

$6 \mathrm{~b} / 1 \times / 2 \mathrm{a} / \mathrm{S} 1-4$

$6 \mathrm{~b} / 1 \mathrm{x} / 2 \mathrm{a}$

$6 b / 1 \times / 2 a / S 5-13$

$6 \mathrm{~b} / 1 \mathrm{x} / 2 \mathrm{a} / \mathrm{S} 7,8,12,13$

$6 \mathrm{~b} / 1 \mathrm{x} / 2 \mathrm{a} / \mathrm{S} 14-16$

$6 \mathrm{~b} / 1 \times / 2 \mathrm{a} / \mathrm{S} 7,8,12,13$

$6 \mathrm{~b} / 1 \mathrm{x} / 2 \mathrm{a}$

$6 \mathrm{~b} / 1 \times / 2 \mathrm{a} / \mathrm{S} 17,18$

$6 b / 1 x / 2 a / S 19,20$ 
6.12. transfer of shoots (S21, S22) to NO 1 medium $+10 \mathrm{mg} \cdot 1^{-1}$ aureomycin

$6 \mathrm{~b} / 1 \mathrm{x} / 2 \mathrm{a} / \mathrm{S} 21,22$

11.12. transfer of shoots S5-S1 2 to soil

23.03.78 grafting of shoots on tomato stock var. Supravite

\begin{tabular}{|c|c|c|}
\hline \multicolumn{3}{|c|}{ (Figure 5) } \\
\hline \multicolumn{3}{|l|}{ Date: } \\
\hline 1.03 .77 & fusion and protoplasts plated on $8 \mathrm{p}$ medium & 7 \\
\hline \multirow{2}{*}{$\begin{array}{l}6.04 \\
6.05\end{array}$} & dilution on agar with $8 \mathrm{p}$ medium & 7a-c \\
\hline & $\begin{array}{l}\text { dilution in agar with } 8 \mathrm{p} \text { medium as toplayer on bottom layer } \\
\text { with MS13K medium }\end{array}$ & $7 a / 14-21$ \\
\hline 11.07 . & transfer of healthy green calli on MSI 3 medium & $7 \mathrm{a} / 20 \mathrm{a}-\mathrm{h}$ \\
\hline 16.08 . & transfer to fresh MS13 medium & $7 a / 20 e-g$ \\
\hline 12.10. & transfer to fresh MS13 medium & $7 \mathrm{a} / 20 \mathrm{e}$ \\
\hline 12.10. & isolation of regenerated shoot $(\mathrm{S} 1)$ to $\mathrm{NO} 1$ medium & $7 \mathrm{a} / 20 \mathrm{e} / \mathrm{S} 1$ \\
\hline 3.11. & transfer of callus to fresh MS13 medium & $7 a / 20 \mathrm{e}$ \\
\hline 3.11 . & isolation of regenerated shoots ( $\mathbf{S 2}, \mathrm{S3})$ to $\mathrm{NO} 1 \mathrm{medium}$ & $7 \mathrm{a} / 30 \mathrm{e} / \mathrm{S} 2,3$ \\
\hline 28.11. & $\begin{array}{l}\text { transfer of } 1 / 2 \text { of callus to MS13 medium and } 1 / 2 \text { to } \mathrm{MS} 13 \text { medium } \\
+50 \mathrm{mg} \cdot 1^{-1} \text { aureomycin }\end{array}$ & $7 \mathrm{a} / 20 \mathrm{e}$ \\
\hline \multirow{5}{*}{$\begin{array}{c}29.11 \\
30.11 \\
3.12 \\
7.12 \\
13.03 .78\end{array}$} & transfer of shoot $\$ 6$ to soil & \\
\hline & transfer of shoots $\mathrm{S} 5, \mathrm{~S} 7$ to soil & \\
\hline & transfer of shoot $\mathrm{S} 4$ to soil & \\
\hline & transfer of shoot $\mathbf{S} 2$ to soil & \\
\hline & grafting of shoots on tomato stock var. Supravite & \\
\hline
\end{tabular}

yellow green to yellow leaves when grown unshaded.

Seeds were sown on Dec. 29, 1976; leaves harvested on March 1, 1977 from large nonflowering plants were sterilized according to Keller and Melchers (22). The leaf pieces were pre-incubated for $25 \mathrm{~min}$ in $0.5 \mathrm{M}$-mannitol at $25^{\circ} \mathrm{C}$ and then treated for 4 hours in enzyme solution ( $\mathrm{pH} 5.8$ ) containing $0.25 \%$ Driselase (Kyowa Hakko Kogyo Co. Ltd., Tokyo, Japan), $0.3 \%$ Cellulase "Onozuka $R-10$ and $0.5 \mathrm{M}$-mannitol.

\subsection{Fusion of protoplasts}

The hybrid plants analysed in this paper originated in a fusion experiment of March 1, 1977. The fusion was performed by placing the protoplasts for $10 \mathrm{~min}$ at $23^{\circ} \mathrm{C}$ in a solution containing $50 \%(w / v)$ polyethyleneglycol 1540 , Cat. No. 0679 Lot No. 279-8 (Polysciences Inc., Warrington $\mathrm{Pa}$., USA), $0.1 \mathrm{M}$-glucose, $3.5 \mathrm{~mm}$ $\mathrm{CaCl}_{2}$ and $0.7 \mathrm{mM}-\mathrm{KH}_{2} \mathrm{PO}_{4}$. The incubation mixture was diluted with $0.08 \mathrm{M}-\mathrm{CaCl}_{2}(\mathrm{pH} \mathrm{10})$. After $20 \mathrm{~min}$ the protoplasts were washed with a solution containing $0.6 \mathrm{M}$-mannitol and 0.05 $\mathrm{M}-\mathrm{CaCl}_{2}$ over a period of $25 \mathrm{~min}$ at $23^{\circ} \mathrm{C}$.

\subsection{Regeneration of the plants investigated for chromosome number and RuBPCase}

The protoplasts were cultured on the very rich medium $8 \mathrm{p}$ of KAO and MICHAYLUK (20) omitting riboflavin. The callus cultures obtained were kept at $24^{\circ} \mathrm{C}$ in rooms with weak continuous light from Osram-Fluora-fluorescence lights supplemented with weak Osram-Nitra lamps (ca. 500-1000 lux). Since the plants originated from different regimes of callus culture transfers the protocols of the 4 relevant groups of plants are detailed in Table I starting with the date and ending with the code number in each line. Representative pictures of group $1 b / 2 h / 3$ are given in Figures $2 a$ and $b$, of group $6 a / 4 z / 6 g$ in Figure 3 , of group $6 b / 1 x / 2 a$ and $2 b$ in Figures 4 and 5 and of group $7 a / 20 e$ in Figure 5. The plants of $6 b / 1 x / 2 a$ and $6 b / 1 x / 2 b$ are morphologically similar and may be genetically identical. Both had as callus developed extensive roots, as is otherwise characteristic for regenerating tomato protoplasts. Aureomycin treatment was used to eliminate bacterial infections presumably originating from the tomato protoplast preparation. 


\subsection{Determination of chromosome numbers}

As far as possible root tips were fixed in ethanol-acetic acid (3:1). From plants which only grew as scions shoot tips, leaf primordia and flower buds were fixed. The chromosomes were stained with orcein-acetic acid and squashed (34).

\subsection{Isolation of RuBPCase}

The procedure for purifying RuBPCase was based on that described previously for the enzyme from Oenothera (14) with some modifications. The leaf material, up to $6 \mathrm{~g}$ fresh weight, was homogenized using a Polytron (Kinematica $\mathrm{GmbH}$ ) in $10 \mathrm{ml} 0.2$ M-sodium borate buffer $\mathrm{pH} 7.5$ containing $10 \mathrm{mM}$-sodium metabisulphite, 5 mM-EDTA, $40 \mathrm{~mm}$-mercaptoethanol and $1 \%(\mathrm{w} / \mathrm{v})$ soluble polyvinylpyrrolidone (PVP) (K25 pharmaceutical grade, Fluka AG, Switzerland). A few drops of octanol were added to prevent foaming during homogenization and to remove the nonprecipitable green material during the subsequent centrifugation. The homogenate was centrifuged at $48,000 \mathrm{~g}$ for $20 \mathrm{~min}$. The supernatant was filtered through glass wool and was then applied to a column of Sephadex G25 (3.2. $\times 20$ $\mathrm{cm}$ ) equilibrated with $16.7 \mathrm{mM}$-sodium phosphate, pH 7.2 containing $10 \mathrm{~mm}$-sodium metabisulphite and $20 \mathrm{~mm}$-mercaptoethanol. The material in the void volume was applied to a DE52 DEAE-cellulose column $(1.6 \times 12 \mathrm{~cm})$ equilibrated with the same phosphate buffer. After extensive washing of the column, RuBPCase was eluted with sodium phosphate buffer containing $0.4 \mathrm{M}-\mathrm{NaCl}$. The fractions containing the enzyme were applied to a Sepharose 6B column $(5.0 \times 50 \mathrm{~cm})$ equilibrated with $50 \mathrm{mM}-\mathrm{Tris}-\mathrm{Cl}$, $\mathrm{pH} 7.5$ containing $100 \mathrm{~mm}-\mathrm{NaCl}, 1 \mathrm{mM}-\mathrm{EDTA}$ and $10 \mathrm{~mm}-$ mercaptoethanol. Solid ammonium sulphate (351 g. $\left.1^{-1}\right)$ was added to the pooled fractions containing RuBPCase and the enzyme was stored as a precipitate at $4^{\circ} \mathrm{C}$.
On some occasions the enzyme was prepared by a shorter procedure in which PVP was omitted from the homogenization buffer and the DEAE-cellulose step was excluded. The effect of this modification is discussed in section 3.1.

\subsection{Preparation of RuBPCase for isoelectric focusing}

Approximately $1 \mathrm{mg}$ RuBPCase was dissolved in $0.25 \mathrm{ml} 1 \mathrm{M}-\mathrm{Tris}-\mathrm{Cl}, \mathrm{pH} 8.6$ containing 6 M-guanidinium chloride (Aristar grade, BDH Chemicals, England) and $2 \mathrm{mg} \cdot \mathrm{ml}^{-1}$ EDTA. After flushing with nitrogen for $15 \mathrm{~min} 1 \mu \mathrm{l}$ of mercaptoethanol was added to each sample. After a further 1 hour $2.6 \mathrm{mg}$ iodoacetic acid dissolved in $1 \mathrm{M}-\mathrm{NaOH}\left(186 \mathrm{mg} \cdot \mathrm{ml}^{-1}\right)$ was added and alkylation was allowed to proceed in the dark for $20 \mathrm{~min}$. The reaction was stopped by addition of a further $1 \mu l$ mercaptoethanol followed by dialysis against deionized water and freeze drying.

The freeze dried samples were re-dissolved in a small volume of water containing 8 M-urea, $2 \%$ ampholyte (LKB ampholine, $\mathrm{pH}$ range 5-7) and $1 \%$ Nonidet $P-40$ prior to isoelectric focusing.

\subsection{Isoelectric focusing of RuBPCase}

Isoelectric focusing was performed at $5^{\circ} \mathrm{C}$ on a flat bed apparatus designed and built by $\mathrm{Mr}$. JAN RASMUSSEN at the Carlsberg Laboratory. A $4.8 \%$ polyacrylamide gel slab $(24 \times 11.5 \times 0.2$ $\mathrm{cm}$ ) containing 8 M-urea, $2 \%$ ampholyte (LKB ampholine, $\mathrm{pH} 5-7$ ), $1 \%$ Nonidet $\mathrm{P}-40$ and polymerized with riboflavin was prepared essentially as described by VESTERBERG(41). $50 \mu \mathrm{l}$ samples were placed in wells cut in the gel near the cathode. A potential of $300 \mathrm{~V}$ was applied for 1 hour followed by $700 \mathrm{~V}$ for 16 hours and $1000 \mathrm{~V}$ for the last $30 \mathrm{~min}$. The gel was fixed, stained and destained according to procedure 'D' described by Vesterberg et al. (42).

Figure 2. Potato-tomato hybrid $1 \mathrm{~b} / 2 \mathrm{~h} / 3$

a) growing on its own roots with filled flowers (possibly because of abnormal chromosome number). Flower colour: very dilute purple (from potato?) but also weak yellow (from tomato?)

b) fibrous roots and rhizome, which is slightly thickened and has produced a shoot with filled flowers. An underground flower bud is also present. 


\section{G. MELCHERS et al.: Potato and tomato hybrids}

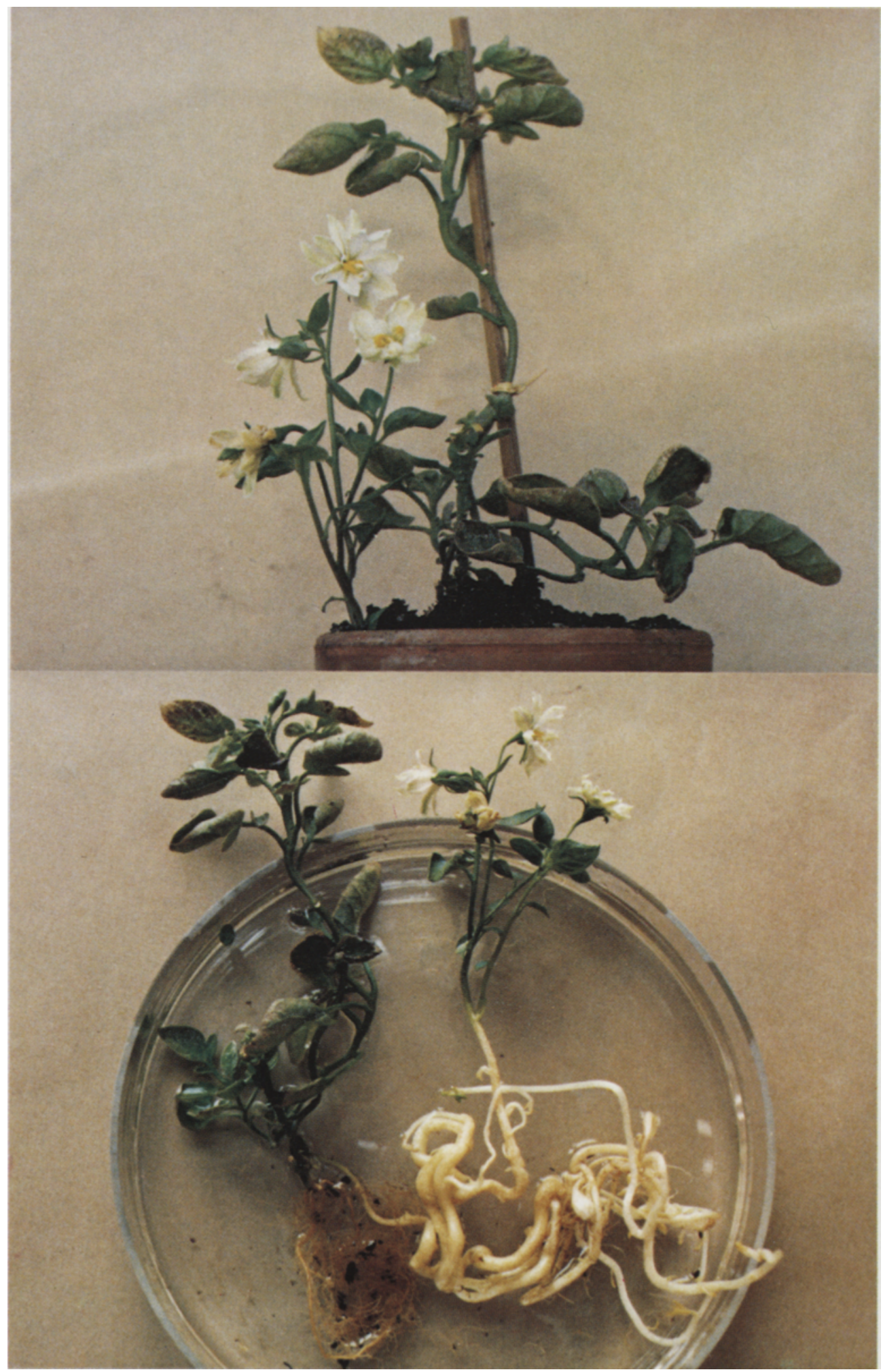




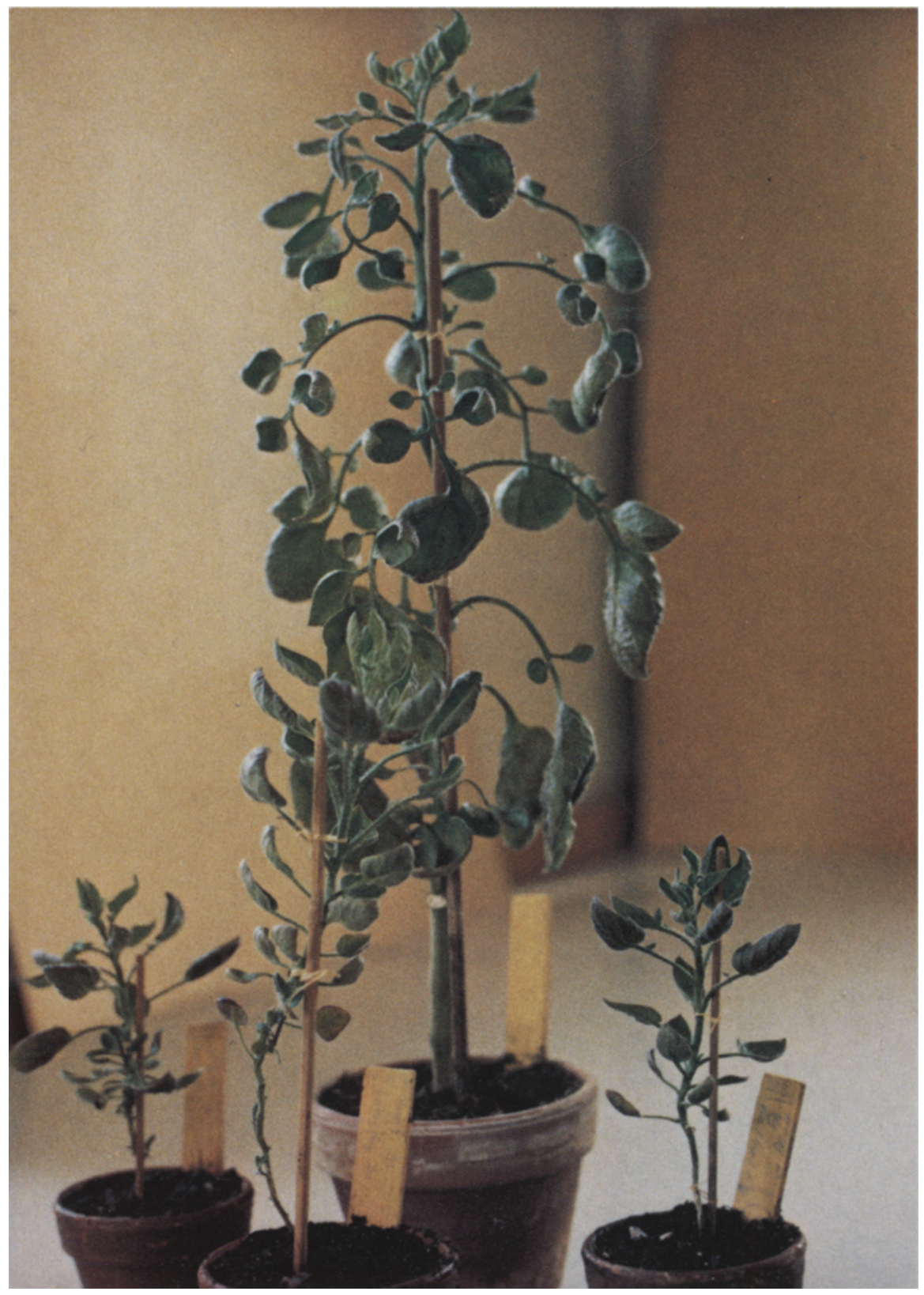

Figure 3. Potato-tomato hybrid $6 \mathrm{a} / 4 \mathrm{z} / 6 \mathrm{~g}$

The plants have anthocyanin rich leaves. The large plant is grafted on tomato var. Supravite and the small plants grow on their own roots.

Figure 4. Potato-tomato hybrid $6 \mathrm{~b} / 1 \mathrm{x} / 2 \mathrm{~b}$

The fruits have probably arisen by parthenocarpy. Results of back crosses not yet known. This hybrid has probably the same genetic constitution as $6 \mathrm{~b} / 1 \mathrm{x} / 2 \mathrm{a}$ (cf. 2.3 ).

Figure 5. Potato-tomato hybrid shoots grafted on tomato stock.

Left: $6 \mathrm{~b} / \mathrm{lx} / 2 \mathrm{a}$ had as callus strong root formation as is characteristic for tomato callus.

Right: $7 \mathrm{a} / 20 \mathrm{e}$ was very difficult to regenerate and to free from infections. 


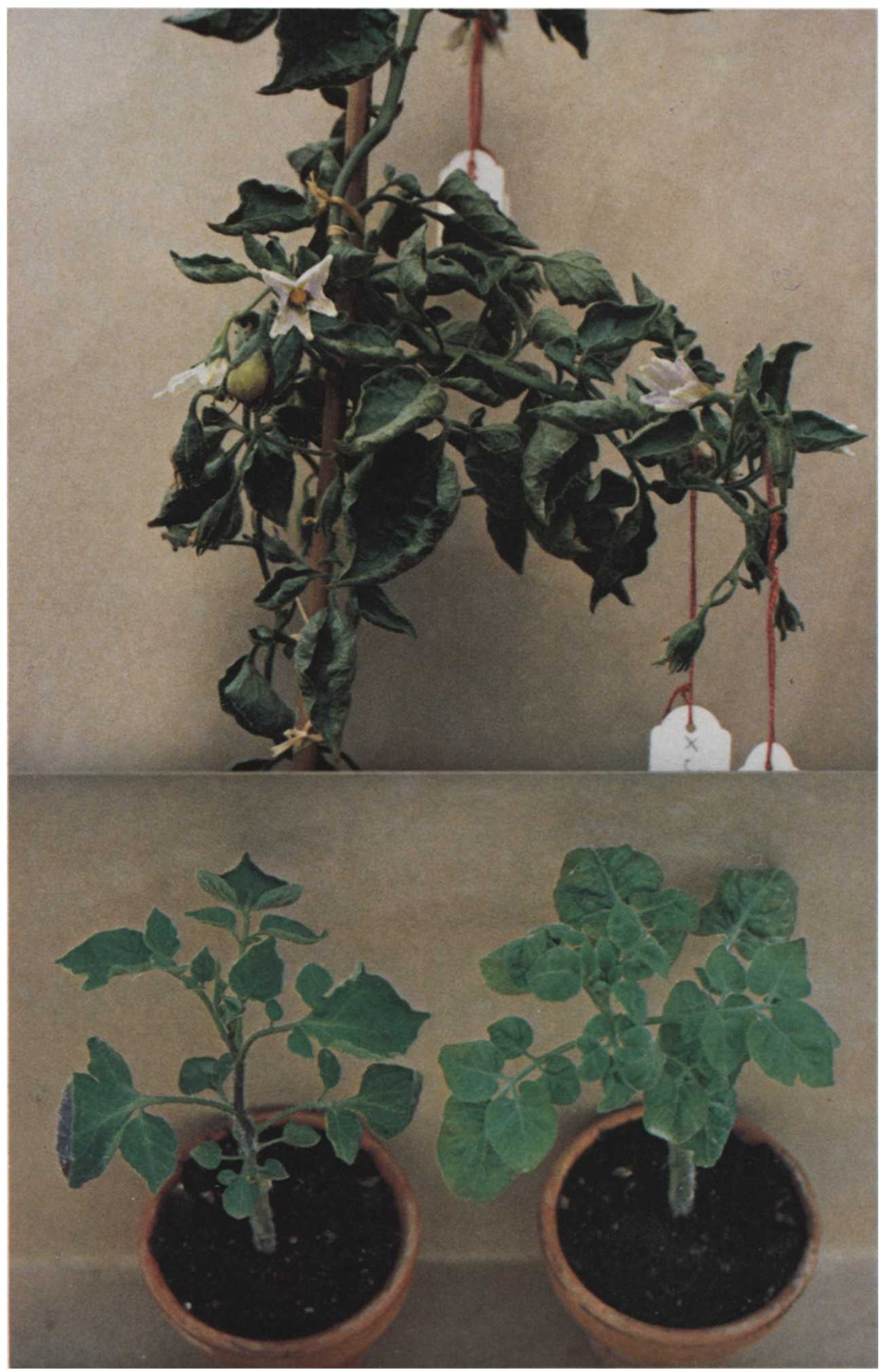




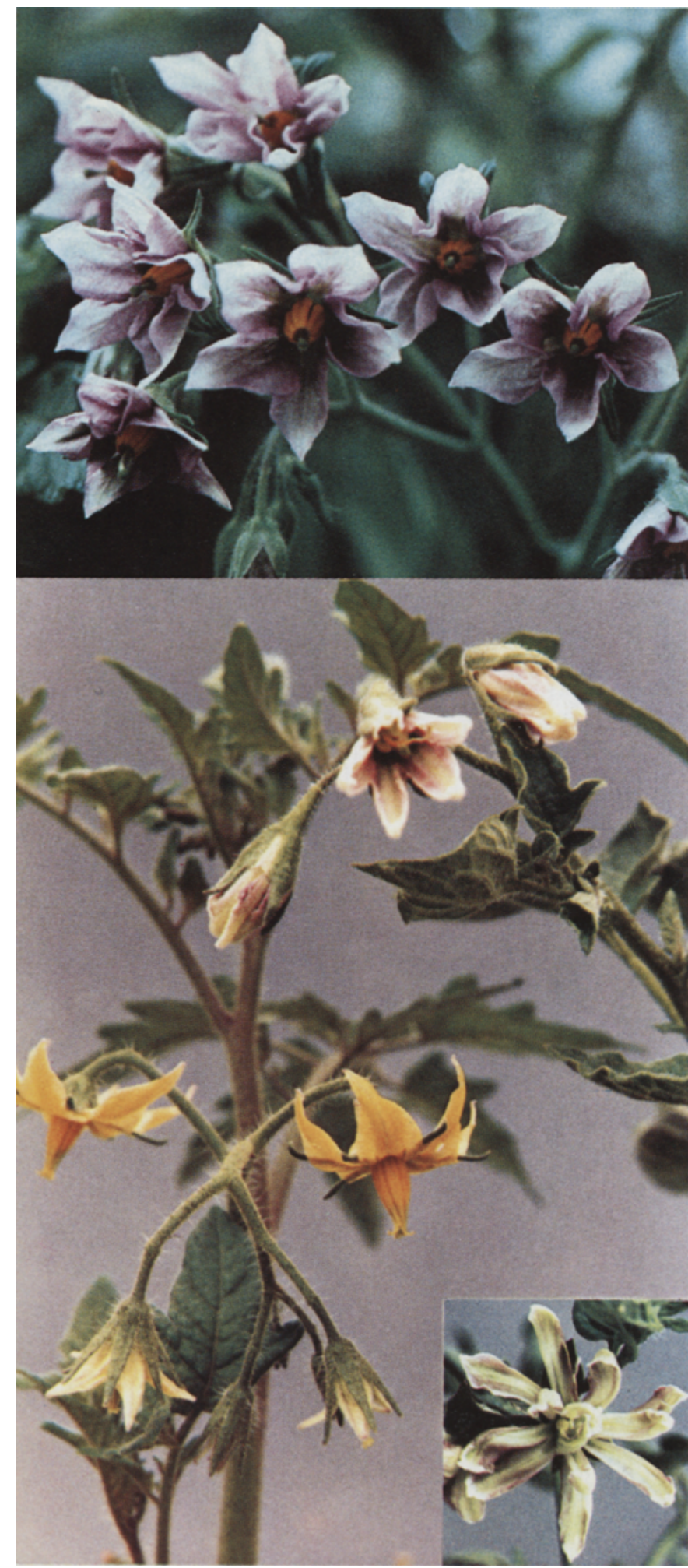

Figure 6. Comparison of flowers from dihaploid potato (top), potato-tomato hybrid $6 \mathrm{~b}$ (middle) and tomato var. Supravite (bottom). Inset: flower of hybrid $1 b$.

\subsection{RuBPCase subunit separation}

The subunits of S-carboxymethylated RuBPCase were separated by gel filtration in 50 mM-ammonium bicarbonate containing $0.5 \%$ SDS on a Sephadex G100 column as described previously (14).

\section{RESULTS}

\subsection{RuBPCase from Solanum tuberosum, stock} HH258 and Lycopersicon esculentum var. cerasiforme, mutant yellow green 6

The purification procedure as described was successfully applied to the isolation of RuBPCase and gave approximate yields of 3$5 \mathrm{mg}$ protein per gram fresh weight leaf material. The RuBPCase prepared from tomato and potato was essentially homogeneous by the criterion of SDS-polyacrylamide gel electrophoresis (C. POULSEN, personal communication). If PVP was absent from the grinding medium and the DEAE-cellulose chromatography step was omitted a pronounced effect on the isoelectric focusing behaviour of the RuBPCase large subunit was observed, as described later, presumably due to interaction of the protein with polyphenols.

Figure 7 shows the polypeptide pattern obtained after isoelectric focusing of S-carboxymethylated RuBPCase from tomato and potato together with the isolated subunits to allow assignment of the individual bands to the two subunits. It can be seen that the small subunit of tomato RuBPCase (tracks 1 and 2) gave rise to 3 bands of different intensity in the pH 5 region of the gel. In the same region of the gel the potato RuBPCase small subunit (tracks 5 and 6) stained as 5 polypeptides of which one was prominent. The patterns of tomato and potato small subunit bands were clearly distinguishable. The number of small subunit polypeptide bands could not be reduced by variation in the extent of reduction or alkylation, and indeed under identical conditions the small subunit of Oenothera hookeri RuBPCase produced a single band (A. A. 


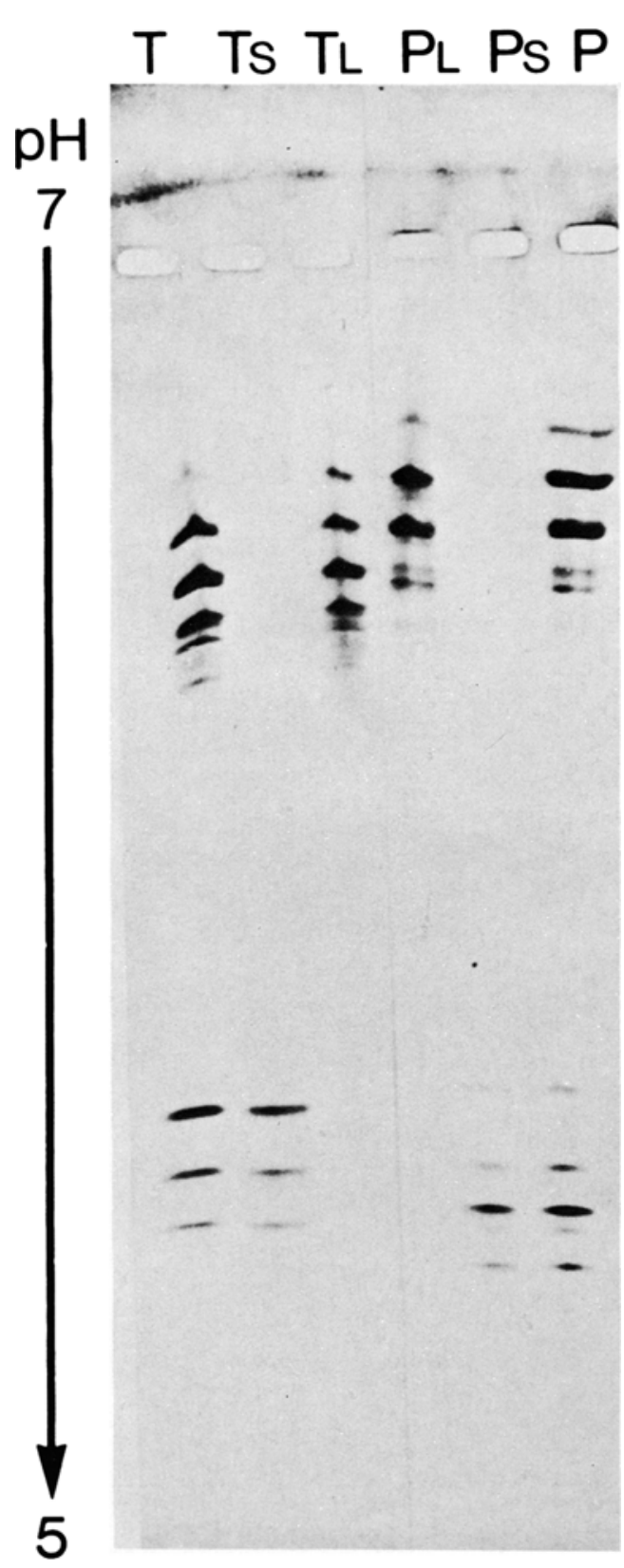

Figure 7. Isoelectric focusing of S-carboxymethylated RuBPCase and its isolated subunits from tomato and potato. (T) Tomato total enzyme, $\left(T_{s}\right)$ tomato small subunit, $\left(T_{L}\right)$ tomato large subunit, $(P)$ potato total enzyme, $\left(P_{S}\right)$ potato small subunit, $\left(P_{L}\right)$ potato large subunit.

HoLDER, unpublished observation). For the large subunit a cluster of bands was obtained in the high $\mathrm{pH}$ region. It can be seen that the potato large subunit (tracks 4 and 6) focused at a higher $\mathrm{pH}$ than the tomato large subunit (tracks 1 and 3).

The effect of the purification procedure is demonstrated by comparing the pattern of large subunit bands from tomato prepared by the shortened procedure (Figure 7, tracks 1 and 3) with the pattern obtained when PVP was included during homogenization and the DEAEcellulose chromatography was performed (Figure 9, track 1), the latter procedure giving a much simpler distribution of polypeptide bands. When the potato enzyme was prepared by the shortened procedure the protein was yellow in solution and the large subunit produced more stained bands, the two most intense were in positions identical to the strongest of the tomato large subunit. This artefact, possibly due to the high content of polyphenols in potato leaves (17) had no effect on the number or position of the small subunit polypeptide bands.

\subsection{RuBPCase of the somatic hybrids}

The plants grown from protoplast fusion products were analyzed by isoelectric focusing of the S-carboxymethylated enzyme prepared by the long purification procedure. In Figure 8

\section{SMALL SUBUNIT}

\section{T $6 a 6 b$ 1b $7 a P$}

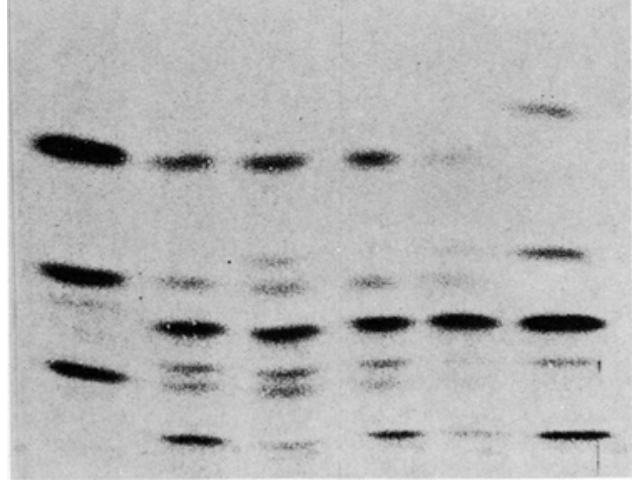

Figure 8. Isoelectric focusing of S-çarboxymethylated RuBPCase small subunit from tomato, potato and the hybrids. (T) tomato, (P) potato, (6a) $6 \mathrm{a} / 4 \mathrm{z} / 6 \mathrm{~g},(6 \mathrm{~b}) 6 \mathrm{~b} /$ $1 x / 2 a$, (1b) $1 b / 2 h / 3$, (7a) $7 a / 20 e$. 


\section{LARGE SUBUNIT}

\section{T P 1b6a 6b 7a T+P}

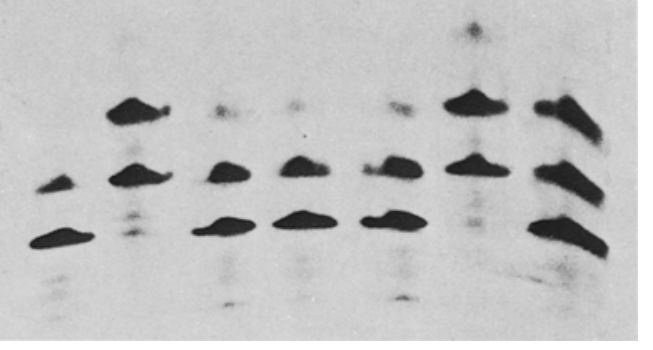

Figure 9. Isoelectric focusing of S-carboxymethylated RuBPCase large subunit from tomato, potato and the hybrids. (T) tomato, $(\mathrm{P})$ potato, $(\mathrm{T}+\mathrm{P})$ mixture of tomato and potato, (lb) $1 \mathrm{~b} / 2 \mathrm{~h} / 3$, (6a) $6 \mathrm{a} / 4 \mathrm{z} / 6 \mathrm{~g}$, (6b) $6 b / 1 x / 2 a,(7 a) 7 a / 20 e$.

the pattern of small subunit bands from these plants is compared with those of tomato and potato. It can be seen that all 4 plants contain the 3 prominent tomato small subunit bands. In addition they all contain the prominent potato small subunit band and two of the faint bands. One of the faint potato small subunit bands is absent in all the hybrids and one is present in only two of the four $(6 \mathrm{~b} / 1 \mathrm{x} / 2 \mathrm{a}$ and $7 \mathrm{a} / 20 \mathrm{e})$; the reason for this is unclear. Relative to the potato bands the staining intensity of the tomato small subunit bands in $7 \mathrm{a} / 20 \mathrm{e}$ is considerably less than in the other plants. These results show that the native RuBPCase in the four plants contains the small subunit products resulting from the expression of both tomato and potato nuclear genes and prove these plants to be somatic hybrids between potato and tomato.

The RuBPCase large subunit polypeptides from the hybrid plants are compared with the tomato and potato large subunit polypeptides in Figure 9. For each large subunit only two prominently stained bands were observed, together with some faint bands. The position of the bands from $1 b / 2 h / 3,6 a / 4 z / 6 g$ and $6 b / 1 x / 2 a$ was identical to those of tomato. The position of the bands of the large subunit from $7 \mathrm{a} / 20 \mathrm{e}$ was identical to those of the large subunit from potato. This is interpreted to indicate that in 3 of the 4 hybrid plants examined the functional chloroplast DNA was derived from tomato whereas in the fourth the chloroplast DNA was derived from potato.

\subsection{Chromosome counts}

In control experiments cultured tomato protoplasts gave rise to callus which developed roots but never shoots. The four regenerated groups of plants investigated here are normal green and do not show the recessive yellow green marker of the tomato used. It can therefore be excluded that the plants are tomatoes. The analysis of RuBPCase (cf. section 3.2) revealed the plants to be somatic hybrids. Ideally their chromosome number should be 48 and the plants amphidiploid and perhaps fertile.

The material was insufficient to establish the chromosome numbers precisely. The numbers counted are presented in Table II. Hybrids $1 \mathrm{~b} /$ $2 \mathrm{~h}, 6 \mathrm{a} / 4 \mathrm{z}$ and $6 \mathrm{~b} / 1 \mathrm{x}$ gave counts around 50 chromosomes which is close to the expected number but in all cases a few extra chromosomes were counted. The poorly growing hybrid $7 \mathrm{a} / 20 \mathrm{e}$ could be a hexaploid with 72 chromosomes. It was noted that this hybrid

\section{Table II}

Chromosome counts of the somatic hybrids of potato and tomato

\begin{tabular}{ccc}
\hline Callus & $\begin{array}{c}\text { Shoot } \\
\text { regenerate }\end{array}$ & Number of chromosomes \\
\hline $1 \mathrm{~b} / 2 \mathrm{~h} / 3$ & $\mathrm{~S} 1$ & $\geqq 50$ \\
- & $\mathrm{S} 3$ & $54-56$ \\
\hline $6 \mathrm{a} / 4 \mathrm{z} / 6 \mathrm{~g}$ & $\mathrm{~S} 1$ & $50-54$ \\
- & $\mathrm{S} 2$ & $\geqq 50$ \\
- & $\mathrm{S3}$ & no division found \\
- & $\mathrm{S} 6$ & $50 \pm 2$ \\
- & $\mathrm{S} 8$ & 54 \\
\hline $6 \mathrm{~b} / 1 \mathrm{x} / 2 \mathrm{a}$ & $\mathrm{S} 1$ & $50-52$ \\
- & $\mathrm{S} 5$ & $\geqq 52$ \\
- & $\mathrm{S} 14$ & no division found \\
\hline $7 \mathrm{a} / 20 \mathrm{e}$ & $\mathrm{S} 2$ & no division found \\
- & $\mathrm{S} 6$ & 72 \\
- & $\mathrm{S} 7$ & $\geqq 60$ \\
- & $\mathrm{S} 12$ & no division found \\
\hline
\end{tabular}


plant contains significantly less staining bands of the tomato small subunit, which may indicate this plant to have arisen by triple fusion of two potato and one tomato protoplast.

\subsection{Morphology of the somatic hybrids}

The plants were transferred into soil under unfavourable conditions and grew poorly during the winter of $1977 / 78$. In the spring a considerable number of them were grafted on tomato stock var. Supravite for growth improvement. Some of these grafts were transferred to Copenhagen on May 17, 1978 for the analysis of RuBPCase. As can be seen from Figures 2 to 6 the hybrids differ in habitus and vigour. They are clearly different in leaf shape and flower morphology from the potato and tomato stocks used for protoplast fusion. Hybrid $1 \mathrm{~b} / 2 \mathrm{~h}$ in Figures $2 \mathrm{a}$ and $2 \mathrm{~b}$ grows on its own roots. The flowers (Figure 6 - inset) are filled and their colour is a highly diluted purple (from potato?) and a weak yellow (from tomato?). The plant has fibrous roots and a slightly thickened thizome (Figure 2b). A shoot with filled flowers has grown from the rhizome and a flower bud has developed under ground. In Figure 3 the hybrid $6 a / 4 z$ is represented by four plants, the large one growing as a scion on tomato stock, the small ones on their own roots. Figure 4 depicts hybrid $6 \mathrm{~b} / 1 \mathrm{x} / 2 \mathrm{~b}$ with probably parthenocarpic fruits and Figure 5 the poorly growing, possibly hexaploid hybrid $7 \mathrm{a} / 20 \mathrm{e}$ at the right and the hybrid $6 b / 1 x / 2 a$ at the left. The latter plant has developed flowers with purple, yellow and white stripes (Figure 6).

To what extent the various characters are due to modifications caused by differences in callus transfer, shoot isolation, transfer to soil or differences in time of grafting cannot be decided at present. Most likely the differences are due to different chromosome constitutions, especially hyperploidy. It is also conceivable that some of the plants are chimeras containing tissues with different chromosome numbers.

\section{DISCUSSION}

The isoelectric focusing of RuBPCase provided phenotypic markers of the chloroplast and nuclear genomes of tomato and potato so that the products of protoplast fusion between these two species could be analyzed. It is clear that the number of polypeptides of different isoelectric behaviour from each subunit could be increased by post-translational modification, by artefacts introduced during cell rupture and enzyme purification or during reduction and alkylation of the protein. Some of these problems have been discussed previously (12) and in the present study care was taken to prevent polyphenol modification of the protein and artefacts arising during reduction and alkylation. With these limitations in mind it can be stated that the isoelectric focusing behaviour shows that the products of both tomato and potato nuclear genomes are present in the RuBPCase oligomer from the hybrids investigated. In addition, the hybrids $\mathrm{Ib} / 2 \mathrm{~h}, 6 \mathrm{a} / 4 \mathrm{z}$ and $6 \mathrm{~b} / 1 \mathrm{x}$ contain the tomato large subunit and hence the tomato chloroplast DNA is functional, whereas in the hybrid $7 \mathrm{a} / 20 \mathrm{e}$ the potato RuBPCase large subunit and therefore the potato chloroplast DNA is present. With this analysis it is impossible to exclude completely the presence of the alternate large subunit as a small percentage of the total. Further analysis of the protein by N-terminal sequencing or peptide mapping will decide these issues.

At the time of fusion the potato protoplasts contained proplastids and the tomato protoplasts fully differentiated chloroplasts. It is an intriguing question if the strong representation of tomato chloroplast DNA in three of the hybrids is due to the differentiated state of the tomato chloroplast at the time of fusion. The fourth hybrid, 7a/20e with its dominating presence of potato chloroplast DNA may have arisen as pointed out in section 3.3 from a triple fusion product and thus from a cell with twice the number of potato plastids than in the case of the other hybrids.

A sexual hybrid of Nicotiana tabacum and Nicotiana knightiana was considered previously not feasible. In connection with the production of somatic hybrids from these two species MALIGA et al. (25) found that this hybrid can be produced sexually at least in the direction $\mathbf{N}$. knightiana $q \times N$. tabacum $\delta$. Also in the case of the somatic Datura hybrids of SCHIEDER(37) sexual hybrids can be obtained with some aid. We suspect that also for the hybrids of 
Lycopersicon esculentum and Solanum tuberosum described in this report means will be found to produce them sexually. ZENKTELER (personal communication) has tried in vitro fertilization, but has so far been unsuccessful. This is perhaps due to the high activity of phenol oxidases in connection with the experimental manipulation.

It is thus possible but not proven that the somatic hybrids described here are the first ones which cannot be produced sexually. If all potato-tomato hybrids, also those with 48 chromosomes, should prove to be sterile their use in plant breeding research would be limited. It is on the other hand likely that the four plants investigated so far are aneuploids and that the true amphidiploid is either already present in the material now available in Tübingen or will be found in new fusion experiments. The fact that both partners are self-fertile gives a good chance that the true amphidiploid is also fertile. Since one now knows what a tomato-potato hybrid plant looks like it will be easier to select them in larger numbers and to identify the true amphidiploid. To what extent practically useful new combinations of genes from the rich assortments of wild, primitive and cultured forms of tomato and potato can be derived by somatic hybridization remains to be seen. In both species monoploid to tetraploid types are known and it is quite possible that combinations of other chromosome types will yield not only viable potato-tomato hybrids by the fusion of protoplasts but also more vigorous hybrids.

\section{ACKNOWLEDGEMENTS}

We gratefully acknowledge the outstanding technical collaboration af GUDRUN LABIB and INGE DoBRIGKEIT at Tübingen and of BøRGE Petersen and ANN-Sofi Steinholtz at Copenhagen. Professor Diter von WeTtSTEIN is warmly thanked for his translation of and critical suggestions for the manuscript. This work was supported generously by the "Gesellschaft für Vegetative Pflanzenvermehrung, Lemförde" during 1976/77 and by the "Deutsche Forschungsgemeinschaft" during $1977 / 78$ for which we express sincere ap- preciation. A. A. HOLDER is the recipient of a Royal Society European Travelling Research Fellowship.

\section{REFERENCES}

1. BeHNKE, M.: Regeneration in Gewebekulturen einiger dihaploider Solanum tuberosum-Klone. $Z$. f. Pflanzenzüchtg. 75, 262-265 (1975)

2. Chan, P.-H. \& S. G. Wildman: Chloroplast DNA codes for the primary structure of the large subunit of Fraction 1 protein. Biochim. Biophys. Acta 277, 677-680 (1972)

3. Chen, K., J. C. Gray \& S. G. Wildman: Fraction 1 protein and the origin of polyploid wheats. Science 190, 1304-1306 (1975)

4. Coen, D. M., J. R. Bedbrook, L. Bogorad \& A. Rich: Maize chloroplast DNA fragment encoding the large subunit of ribulose bisphosphate carboxylase. Proc. Nat. Acad. Sci. (USA) 74, 5487-5491 (1977)

5. Dobberstein, B., G. Blobel \& N.-H. Chua: In vitro synthesis and processing of a putative precursor for the small subunit of ribulose-1,5bisphosphate carboxylase of Chlamydomonas reinhardtii. Proc. Nat. Acad. Sci. (USA) 74, 10821085 (1977)

6. Dudits, D., I. Rasko, G. Hadlaczky \& A. LumaDE-FARIA: Fusion of human cells with carrot protoplasts induced by polyethylene glycol. Heriditas 82, 121-124 (1976)

7. Dudits, D., G. Hadlaczky, E. Levi, O. Fejér \& G. LAZAR: Somatic hybridization of Daucus carota and $D$. cepillifolius by protoplast fusion. Theor. Appl. Genet. 51, 127-132 (1977)

8. Gatenby, A. A. \& E. C. Cocking: Polypeptide composition of Fraction 1 protein subunits in the genus Petunia. Plant Sci. Letts. 10, 97-101 (1977)

9. Gatenby, A. A. \& E. C. Cocking: Fraction 1 protein and the origin of the European potato. Plant Sci. Letts. 12, 177-181 (1978)

10. Gelvin, S., P. HeizmanN \& S. H. Howell: Identification and cloning of the chloroplast gene coding for the large subunit of ribulose 1,5bisphosphate carboxylase from Chlamydomonas reinhardtii. Proc. Nat. Acad. Sci. (USA) 74, 31933197 (1977)

11. Gray, J. C., S. D. Kung, S. G. Wildman \& S. J. SHEEN: Origin of Nicotiana tabacum $L$. detected by polypeptide composition of Fraction 1 protein. Nature 252, 226-227 (1974)

12. Gray, J. C., S. D. Kung \& S. G. Wildman: Polypeptide chains of the large and small subunits of Fraction 1 protein from tobacco. Archiv. Biochem. Biophys. 185, 272-281 (1978) 
13. Highfield, P. E. \& R. J. Ellis: Synthesis and transport of the small subunit of chloroplast ribulose bisphosphate carboxylase. Nature 271, 420-424 (1978)

14. Holder, A. A.: Ribulose 1,5-diphosphate carboxylase from Oenothera: Purification and a peptide mapping procedure for the subunits. Carlsberg Res. Commun. 41, 321-334 (1976)

15. Hollingshead, L.: A lethal factor in Crepis effective only in an interspecific hybrid. Genetics $15,114-140$ (1930)

16. Hollingshead, L.: Cytological investigations of hybrids and hybrid derivatives of Crepis capillaris and Crepis tectorum. Univ. Calif. Publ. Agri. Sci. 6, 55-94 (1930)

17. KAHL, G. \& M. MÚlLeR: Phenol induced inactivation of phosphoglucomutase in extracts from different organs of the potato plant. Biochem. Physiol. Pflanzen 169, 281-288 (1976)

18. KAO, K. N.: Chromosomal behavior in somatic hybrids of soybean - Nicotiana glauca. Molec. gen. Genet. 150, 225-230 (1977)

19. KaO, K. N. \& M. R. MichayluK: A method for high frequency intergeneric fusion of plant protoplasts. Planta (Berlin) 115, 355-367 (1974)

20. KAO, K. N. \& M. R. MiChAYLUK: nutritional requirements for growth of Vicia hajastana cells and protoplasts at very low density in liquid media. Planta (Berlin) 126, 105-110 (1975)

21. Kawashima, N. \& S. G. Wildman: Studies on Fraction 1 protein. IV. Mode of inheritance of the primary structure in relation to whether chloroplast or nuclear DNA contains the code for a chloroplast protein. Biochim. Biophys. Acta 262, 42-49 (1972)

22. Keller, W. A. \& G. Melchers: The effect of high $\mathrm{pH}$ and calcium on tobacco leaf protoplast fusion. Z. Naturforsch. 28c, 737-741 (1973)

23. KUNG, S. D.: Tobacco Fraction 1 protein: a unique genetic marker. Science 191, 429-434 (1976)

24. Kung, S. D., J. C. Gray \& S. G. Wildman: Polypeptide composition of Fraction 1 protein from parasexual hybrid plants in the genus Nicotiana. Science 187, 353-355(1975)

25. Maliga, P., Z. R. Kiss, A. H. Nagy \& G. Lazar: Genetic instability in somatic hybrids of Nicotiana tabacum and Nicotiana knightiana. Molec. gen. Genet. 163, 145-152(1978)

26. Melchers, G.: Genetik und Evolution. Bericht eines Botanikers. Z. Vererbungslehre 76, 229-259 (1939)

27. MelChers, G.: Microbial techniques in somatic hybridisation by fusion of protoplasts. In: Internat. Cell Biol. 1976-77, B. R. Brinkley and K. R.
Porter, eds. Papers presented at the I. Internat. Congress on Cell Biology, Boston Mass. 1976. The Rockefeller University Press 1977, pp. 207215.

28. Melchers, G.: Potatoes for combined somatic and sexual breeding methods; plants from protoplasts and fusion of protoplasts of potato and tomato. In: Production of natural compounds by cell culture methods. A. W. Alfermann and E. Reinhard, eds. Proc. of an Internat. Symp. on plant cell culture. Ges. f. Strahlen- und Umweltforschung, München, pp. 306-311 (1978)

29. Melchers, G. \& G. LabiB: Somatic hybridisation of plants by fusion of protoplasts. I. Selection of light resistant hybrids of "haploid" light sensitive varieties of tobacco. Molec. gen. Genet. 135, 277. 294 (1974)

30. Melchers, G. \& M. D. SaCristan: Somatic hybridisation of plants by fusion of protoplasts. II. The chromosome numbers of somatic hybrid plants of 4 different fusion experiments. La Culture des Tissues et de Cellules des Végétaux, Travaux dédiés à la mémoire de Georges Morel, R. Gautheret, ed., Masson, Paris, pp. 169-177 (1977)

31. Pogliaga, H. H.: Hibrido intergenerico "Nicotiana $\times$ Petunia". Rev. Argent. Agron. 19, 171-178 (1952)

32. Power, J. B., E. M. Frearson, C. Hayward, D. George, P. K. Evans, S. F. Berry \& E. C. CockIng: Somatic hybridisation of Petunia hybrida and $P$. parodii. Nature 263, 500-502 (1976)

33. Roy, H., R. Patterson \& A. T. Jagendorf: Identification of the small subunit of ribulose bisphosphate carboxylase as a product of wheat leaf cytoplasmic ribosomes. Archiv. Biochem. Biophys. 172, 64-73 (1976)

34. Sacristán, M. D. \& G. Melchers: The caryological analysis of plants regenerated from tumorous and other callus cultures of tobacco. Molec. gen. Genet. 105, 317-333 (1969)

35. Sakano, K., S. D. Kung \& S. G. Wildman: Identification of several chloroplast DNA genes which code for the large subunit of Nicotiana Fraction 1 proteins. Molec. gen. Genet. 130, 9197 (1974)

36. SChIEDER, O.: Fusionen zwischen Protoplasten von Spaerocarpos donnellii Aust.-Mutanten. Biochem. Physiol. Pflanzen 165, 433-435 (1974)

37. Schieder, O.: Somatic hybrids of Datura innoxia Mill. + Datura discolor Bernh. and of Datura innoxia Mill. + Datura stramonium $L$. var. tatula $L$. I. Selection and Characterisation. Molec. gen. Genet. 162, 113-120(1978) 
38. Smith, H. H., K. N. Kao \& N. C. Combatti: Interspecific hybridization by protoplast fusion in Nicotiana. J. Hered. 67, 123-128 (1976)

39. SteEr, M. W. \& D. Kernoghan: Nuclear and cytoplasmic genome relationships in the genus Avena: Analysis by isoelectric focusing of ribulose bisphosphate carboxylase subunits. Biochem. Genet. 15, 273-286 (1977)

40. Takebe, I., G. Labib \& G. Melchers: Regeneration of whole plants from isolated mesophyll protoplasts of tobacco. Naturwissenschaften 58, 318-320(1971)

41. VesterberG, O.: Isoelectric focusing of proteins in thin layers of polyacrylamide gel. Sci. Tools 20 , 22-29 (1973)

42. Vesterberg, O., L. Hansen \& A. Suósten: Stain- ing of proteins after isoelectric focusing in gels by new procedures. Biochim. Biophys. Acta 491, 160-166 (1977)

43. Wallin, A., K. Glimelius \& T. ERiksson: Effects of polyethyleneglycol on aggregation and fusion of Daucus carota protoplasts. In: Third International Congress of Plant Tissue and Cell Culture, Abstr. No. 207 (1974)

44. WetTER, L. R.: Isoenzyme patterns in soybeanNicotiana somatic hybrid cell lines. Molec. gen. Genet. 150, 231-236(1977)

45. Zenkteler, M. \& G. Melchers: In vitro hybridization by sexual methods and by fusion of somatic protoplasts. Theor. Appl. Genet. 52, 8190 (1978) 